\title{
Comparison of source apportionment approaches and analysis of non-linearity in a real case model application
}

Claudio A. Belis ${ }^{1}$, Guido Pirovano ${ }^{2}$, Maria Gabriella Villani ${ }^{3}$, Giuseppe Calori ${ }^{4}$, Nicola Pepe ${ }^{4}$, Jean Philippe Putaud ${ }^{1}$

${ }^{1}$ European Commission, Joint Research Centre, via Fermi 2748, 21027 Ispra (VA), Italy

${ }^{2}$ RSE Spa, via Rubattino 54, 20134, Milan, Italy

${ }^{3}$ ENEA Laboratory of Atmospheric Pollution, via Fermi 2748, 21027 Ispra (VA), Italy

${ }^{4}$ ARIANET s.r.l. via Gilino, 9 - 20128 Milan (MI) - Italy

\section{Supplementary Material}

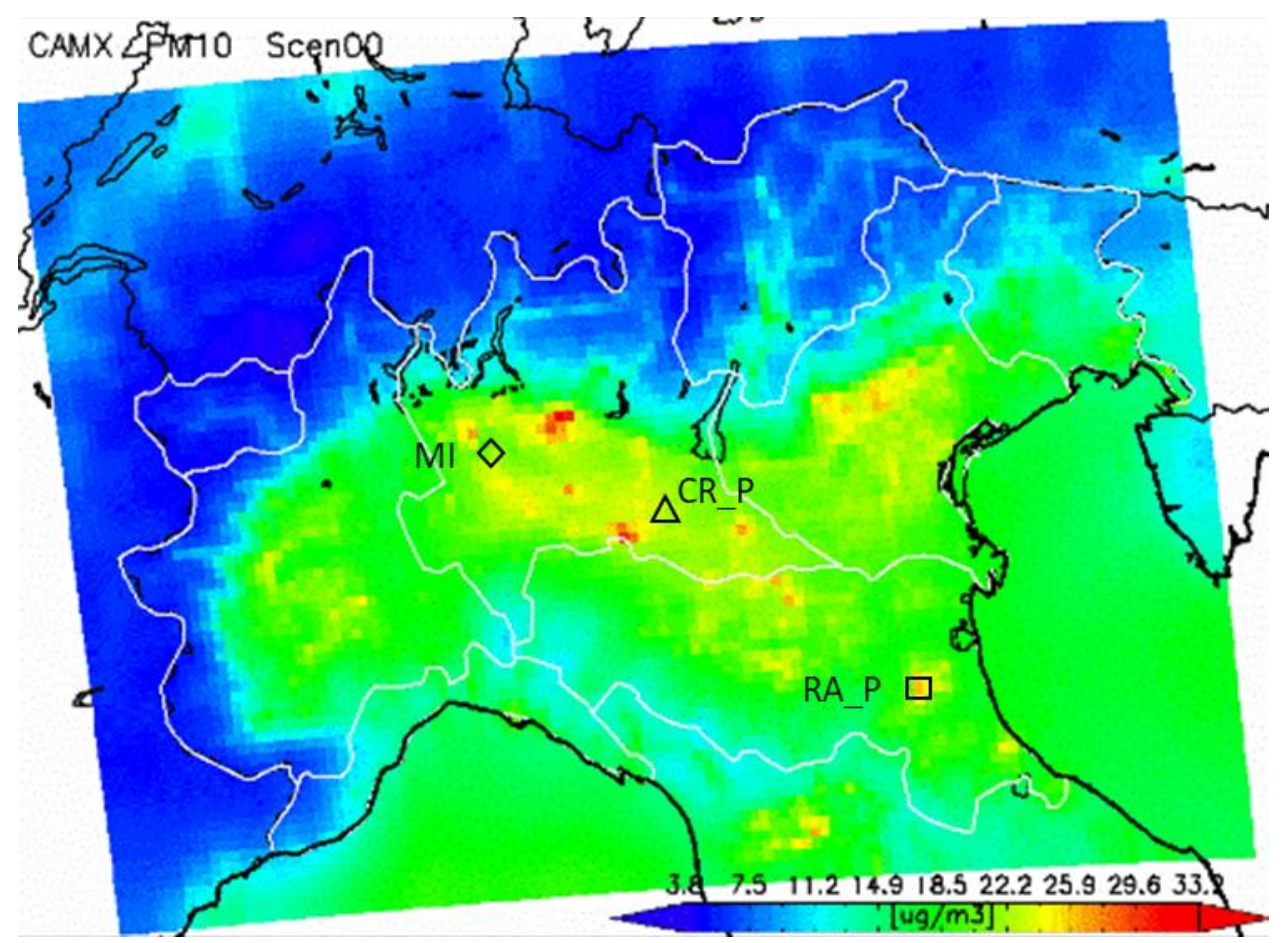

Figure S1. PM10 yearly mean concentrations for 2010 obtained with CAMx. The empty markers indicate the sites for which a detailed analysis of interaction terms and gas ratio was carried out. 


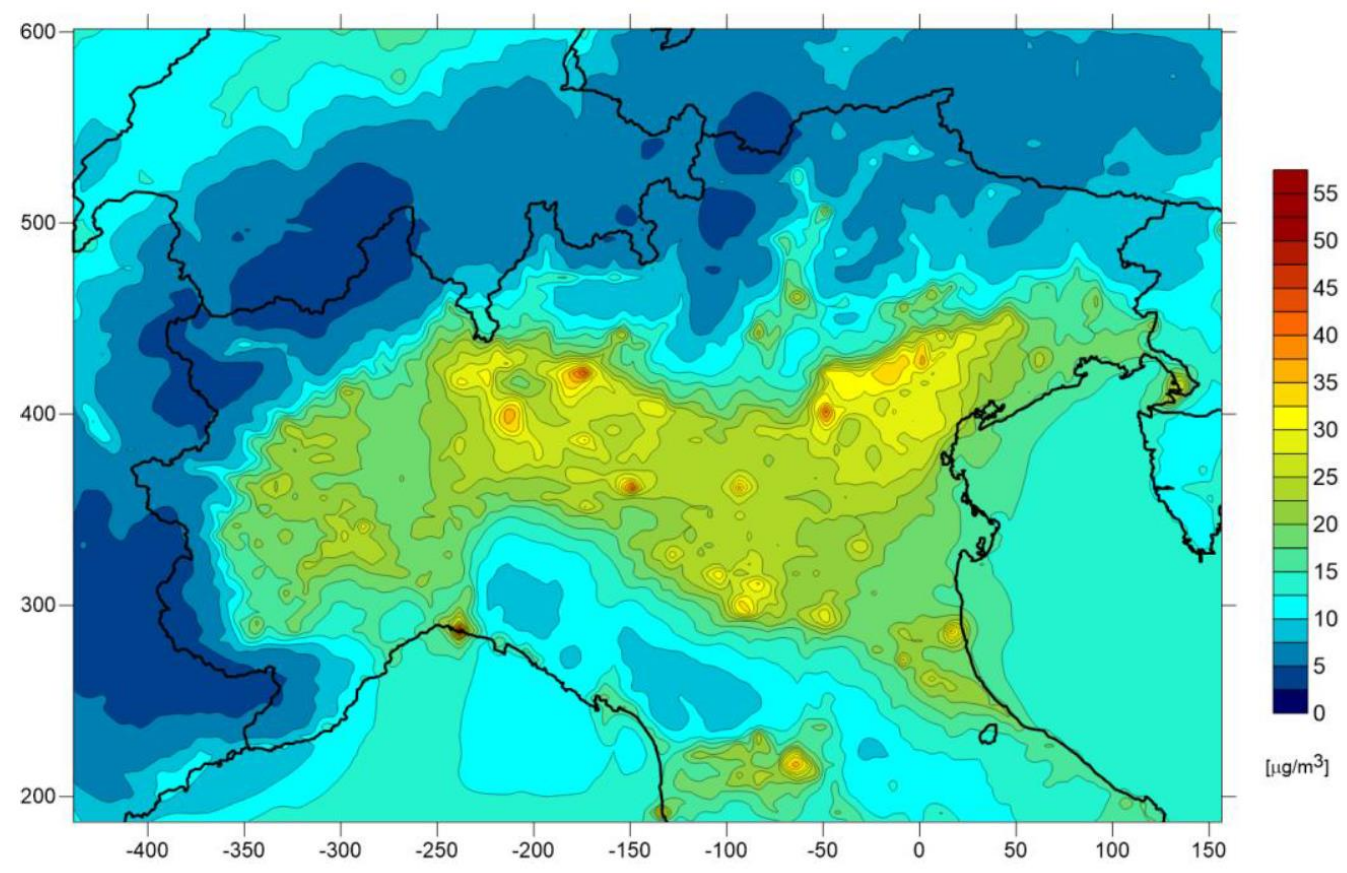

Figure S2. PM10 yearly mean concentrations for 2010 obtained with FARM

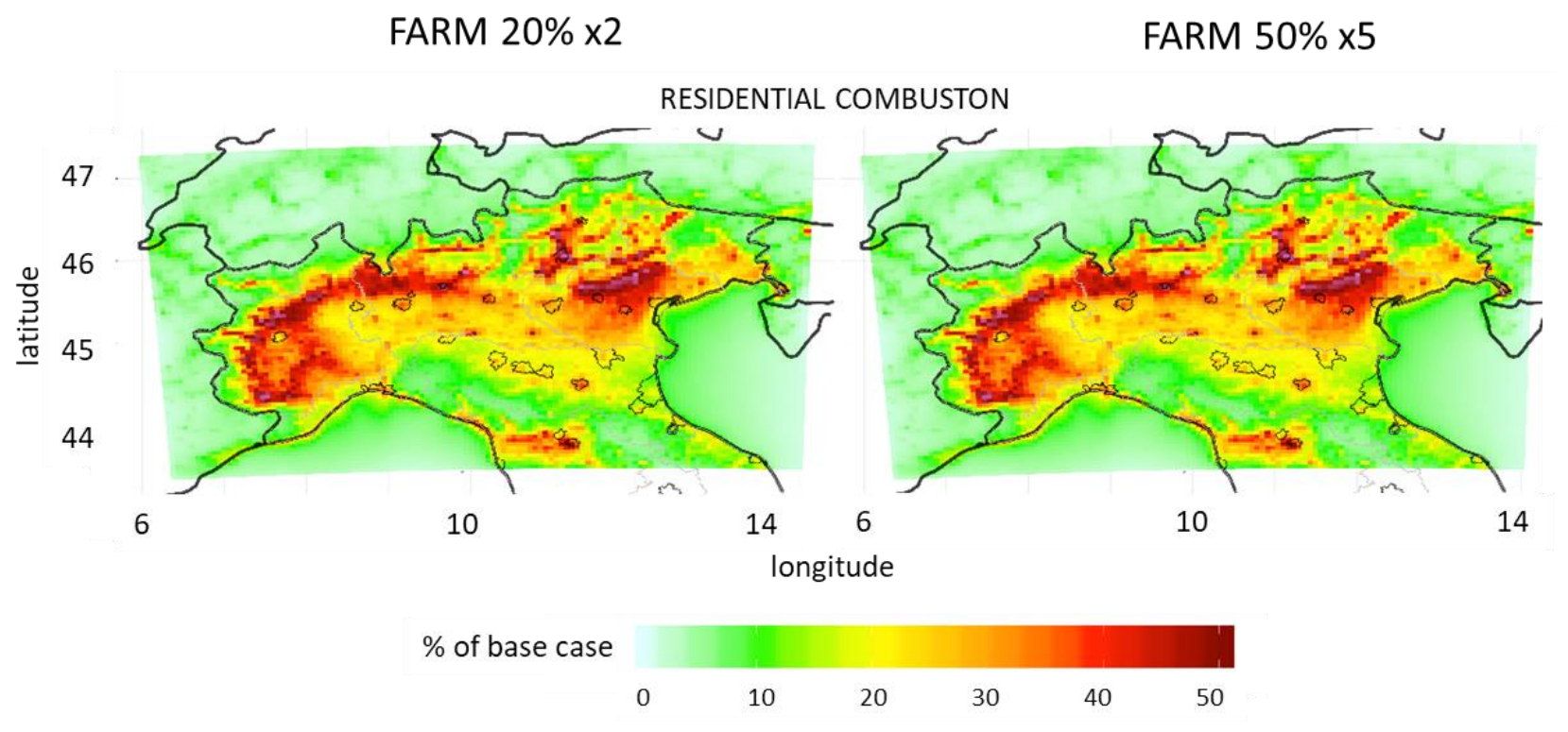

Figure S3. Annual average impacts of RES expressed as proportion of the base case for $\mathbf{2 0} \%$ and $\mathbf{5 0} \%$ ERLs. 

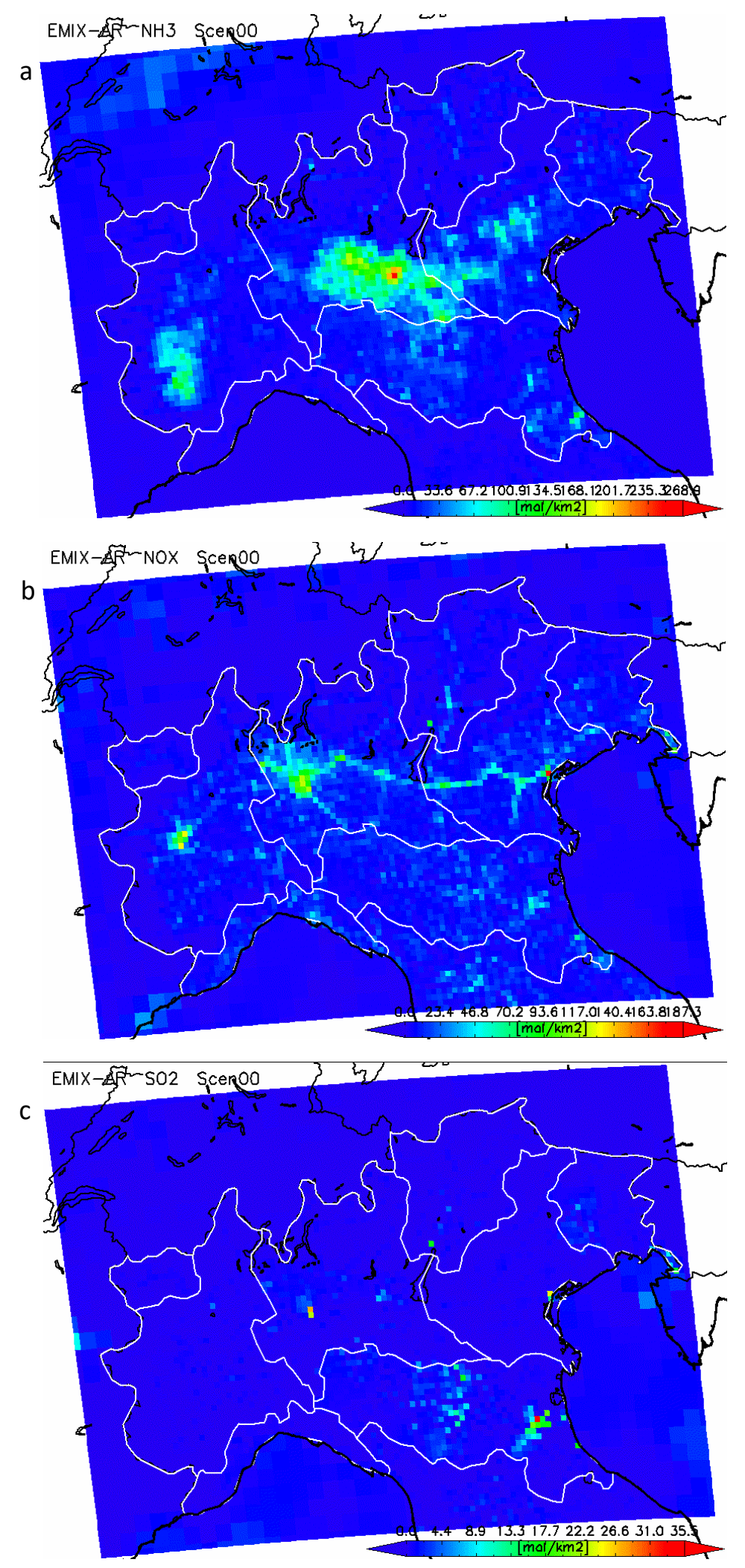

Figure S4. Emissions of $\mathrm{NH}_{3}(\mathrm{a}), \mathrm{NO}_{\mathbf{x}}(\mathrm{b})$ and $\mathrm{SO}_{2}(\mathrm{c})$ in the studied domain in 2010. 

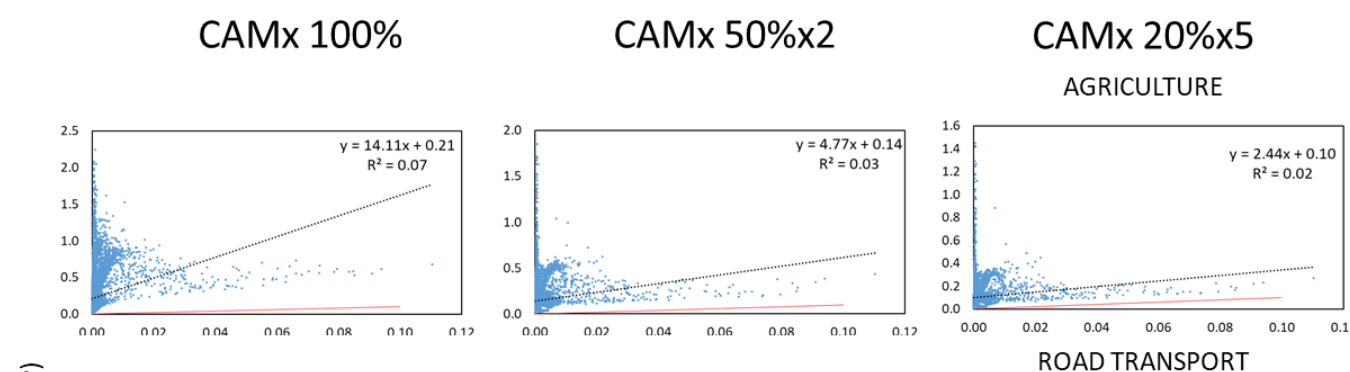

FARM 50\%x2

FARM $20 \% \times 5$
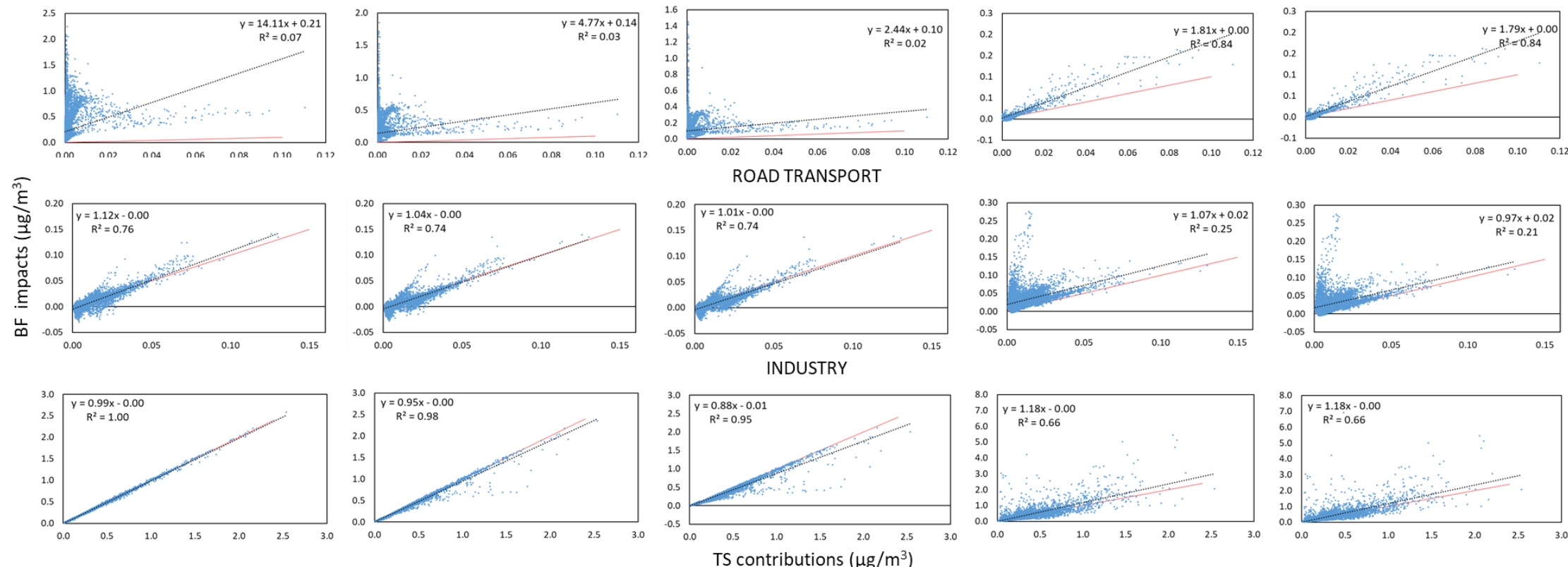

Figure S5. Scatter plots of the BF impacts (CAMx and FARM) on particulate sulfate versus the TS contributions (PSAT) for 20\%, 50\% and 100\% ERLs. Agriculture (AGR) industry (IND) and traffic (TRA). 


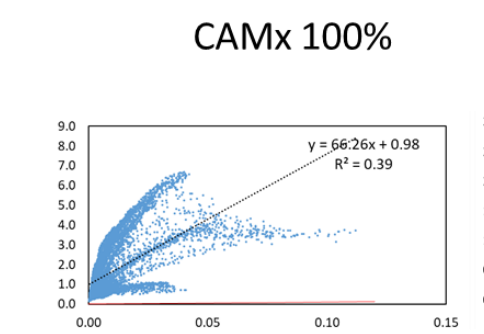

AGRICULTURE
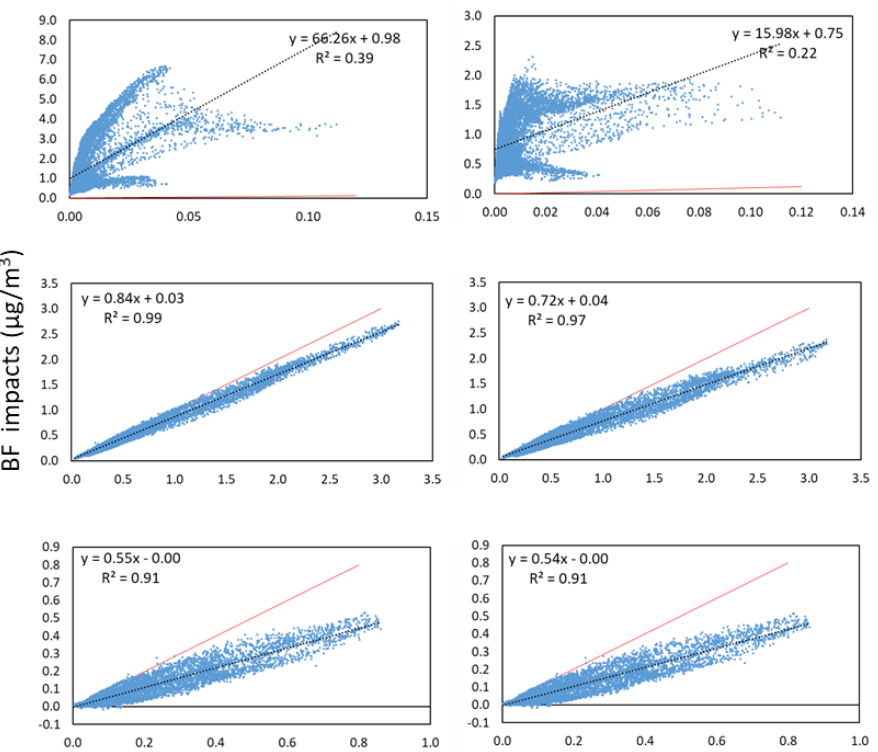

INDUSTRY
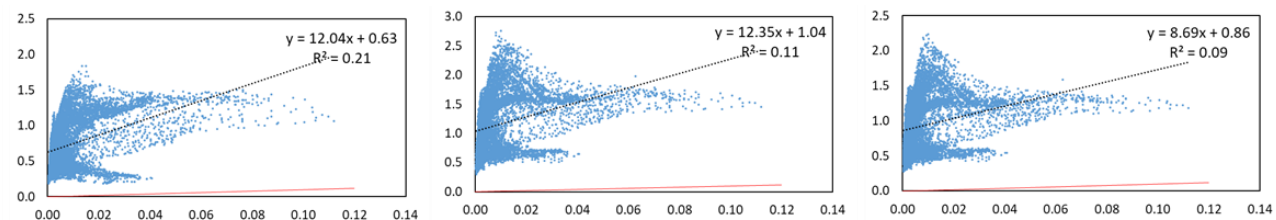

ROAD TRANSPORT
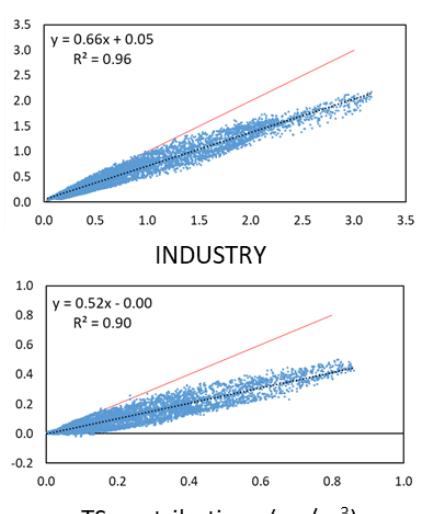

TS contributions $\left(\mu \mathrm{g} / \mathrm{m}^{3}\right)$
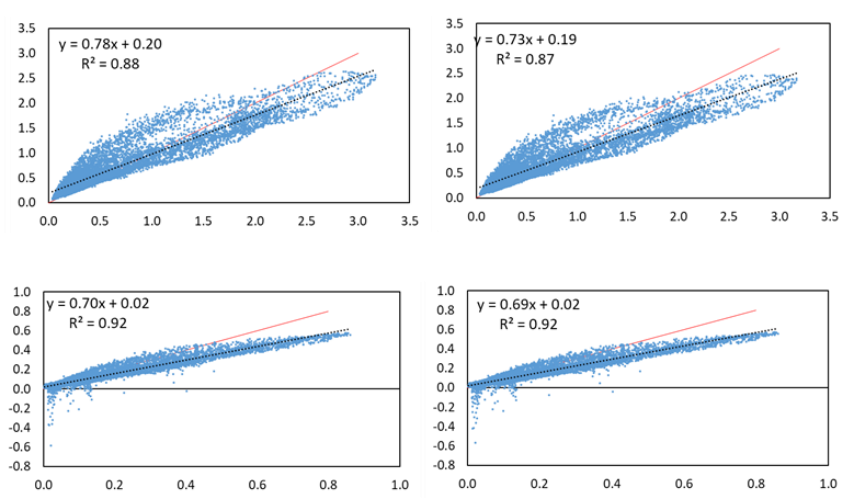

Figure S6. Scatter plots of the BF impacts (CAMx and FARM) on particulate nitrate versus the TS contributions (PSAT) for 20\%, 50\% and 100\% ERLs. Agriculture (AGR), industry (IND) and traffic (TRA). 

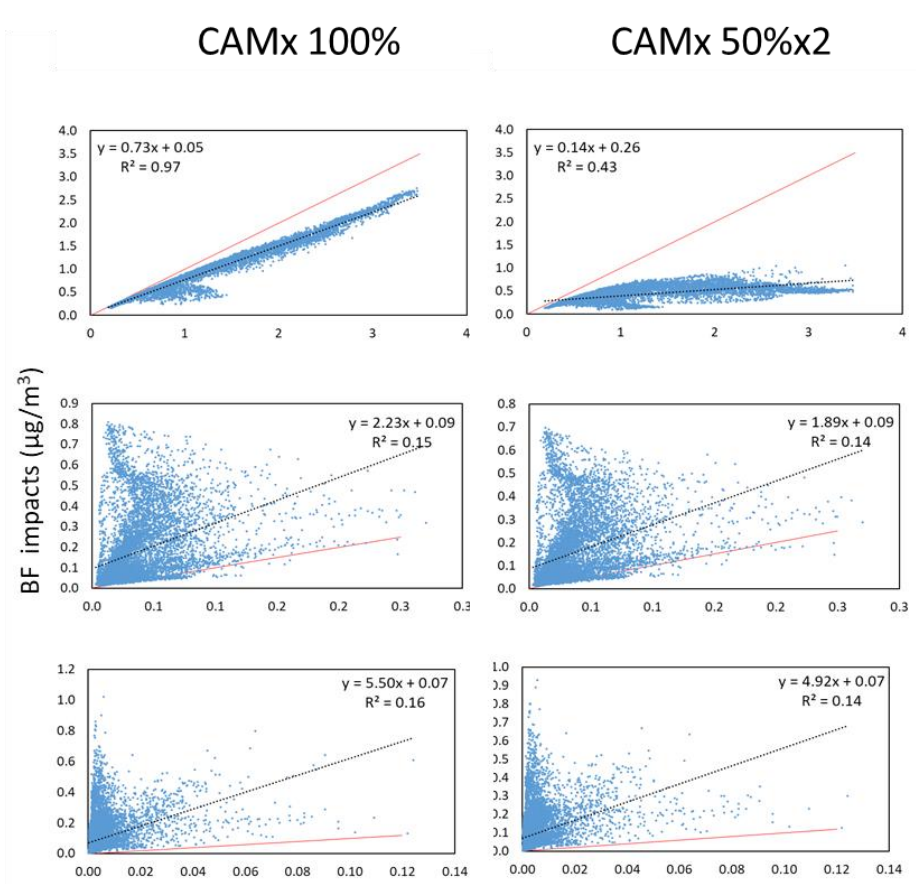

$$
\text { . }
$$

Figure S7. Scatter plots of the BF industry (IND) and traffic (TRA). 


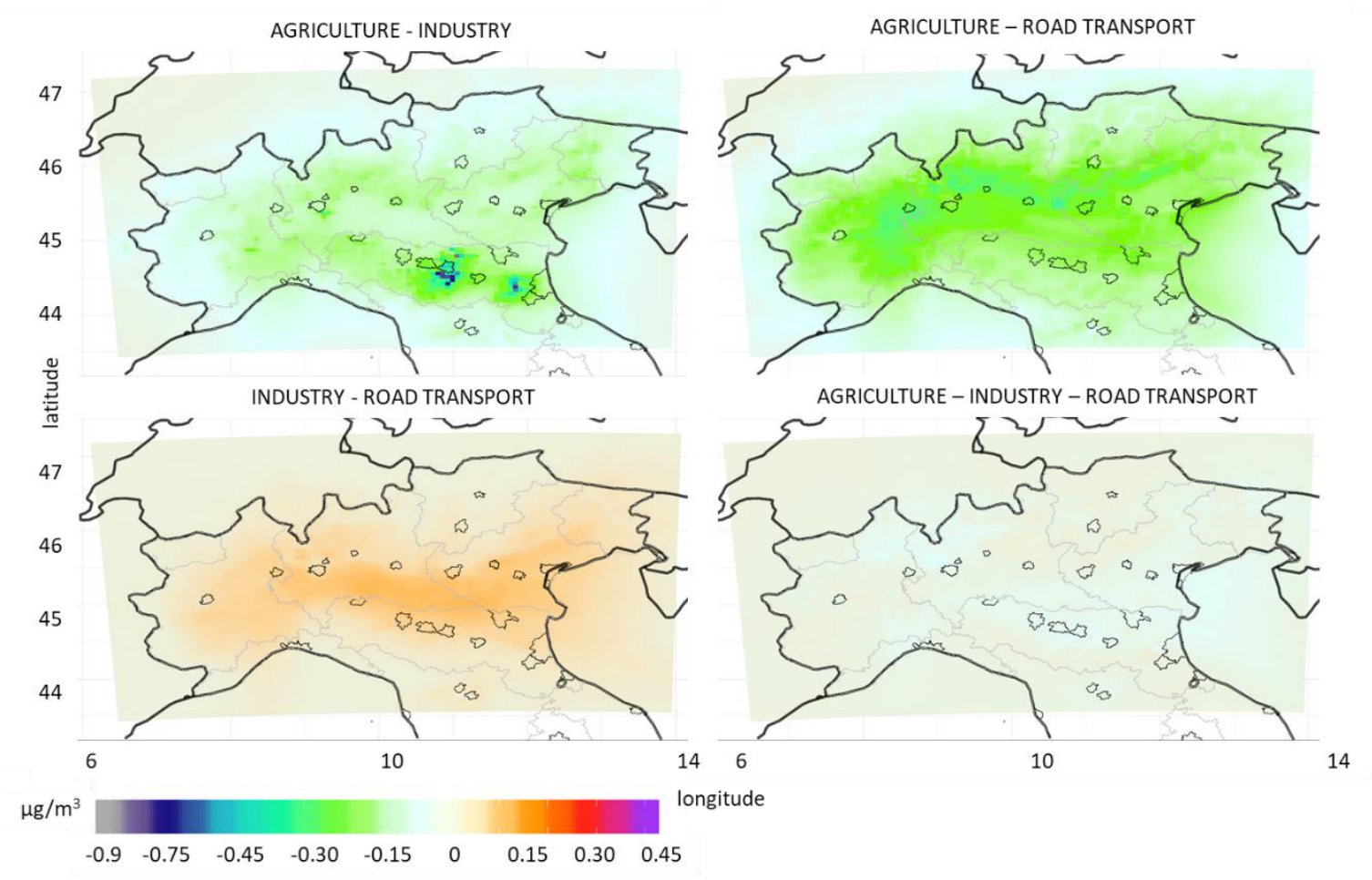

Figure S8 Map of the binary and ternary interaction terms of the PM 10 factor decomposition for AGR, IND and TRA in the CAMx $50 \%$ scenarios.

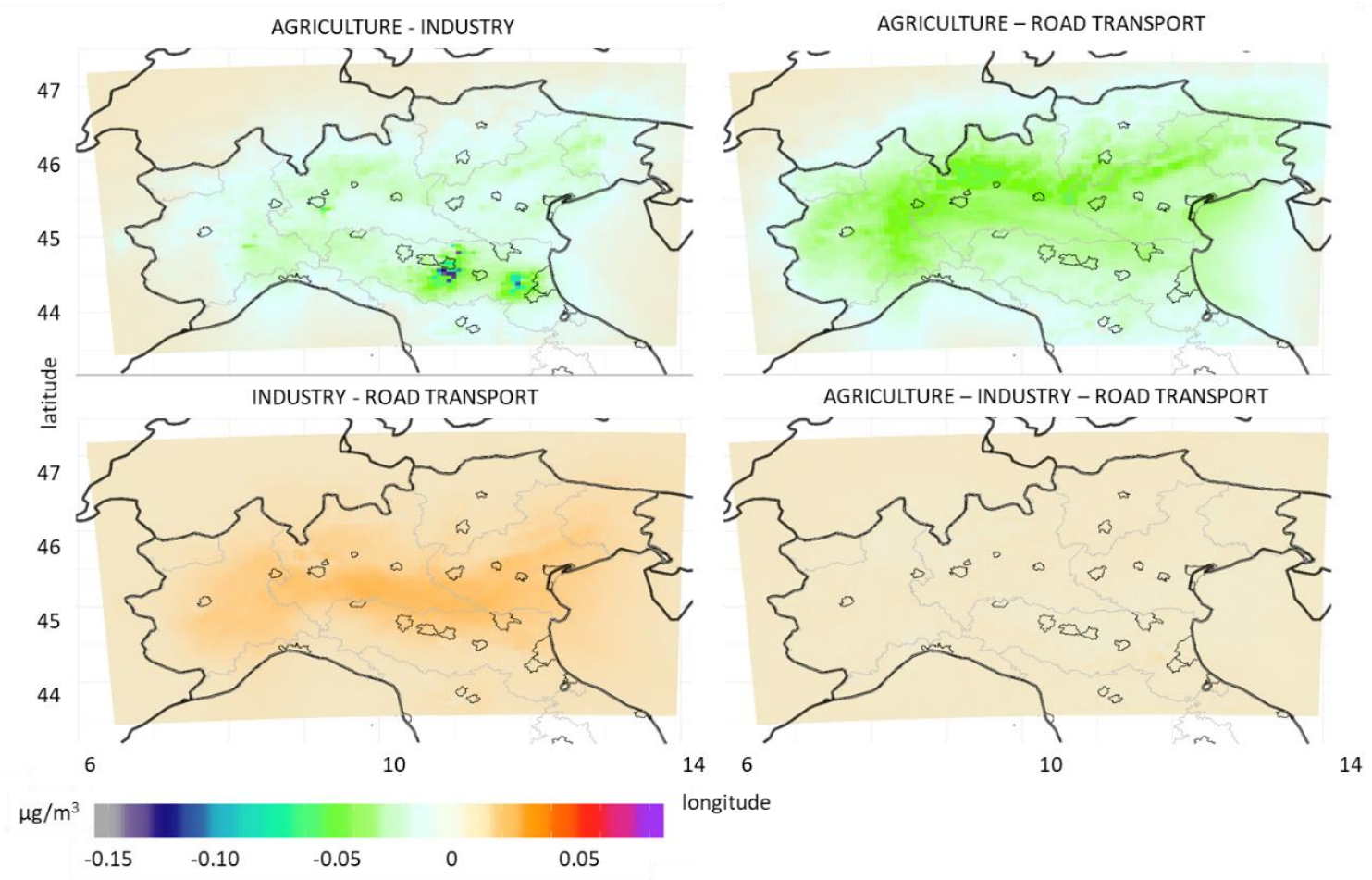

Figure S9 Map of the binary and ternary interaction terms of the $\mathrm{PM}_{10}$ factor decomposition for AGR, IND and TRA in the CAMx $20 \%$ scenarios. 


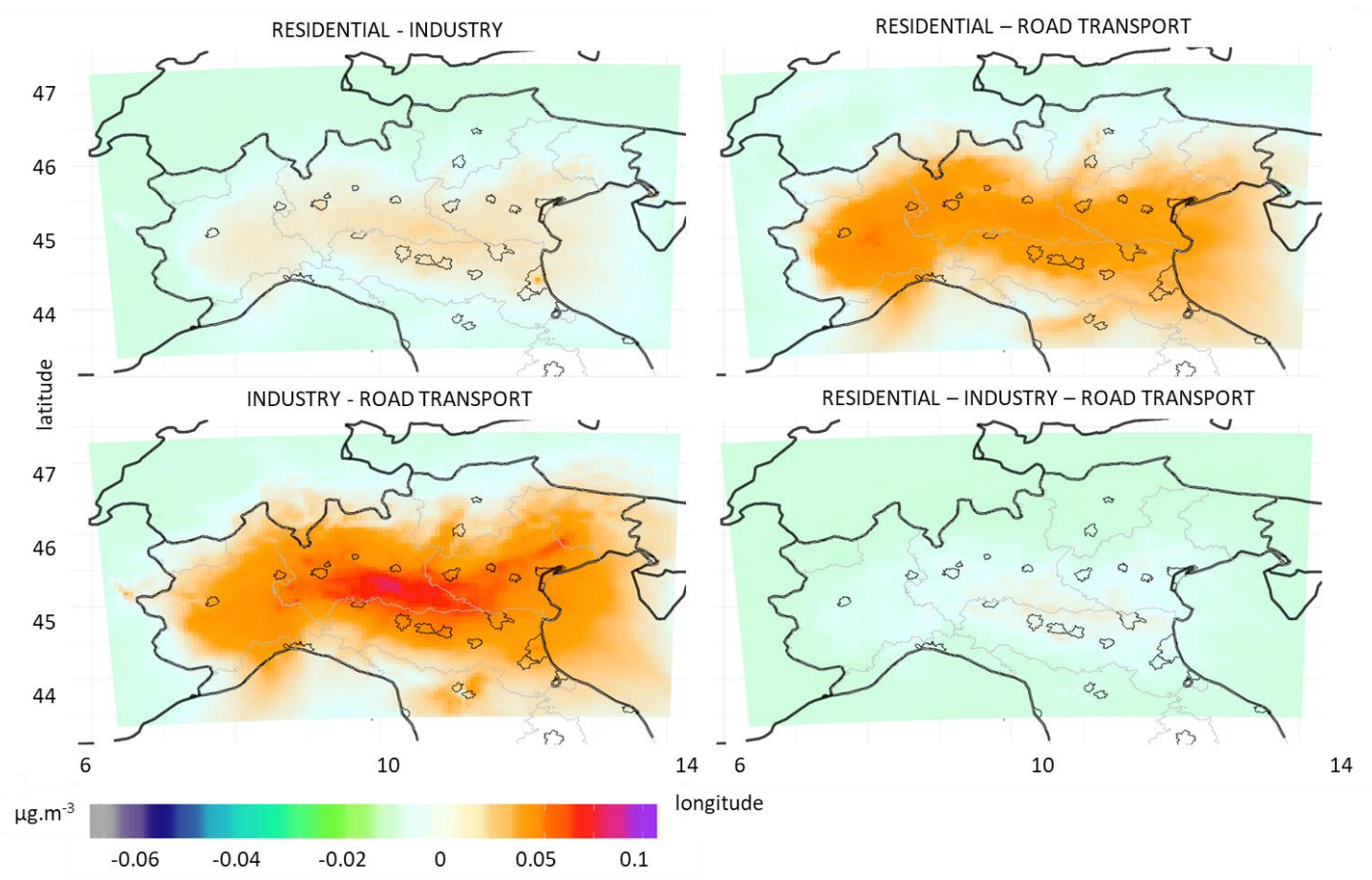

Figure S10 Map of the binary and ternary interaction terms of the PM $_{10}$ factor decomposition for RES, IND and TRA in the FARM $50 \%$ scenarios.

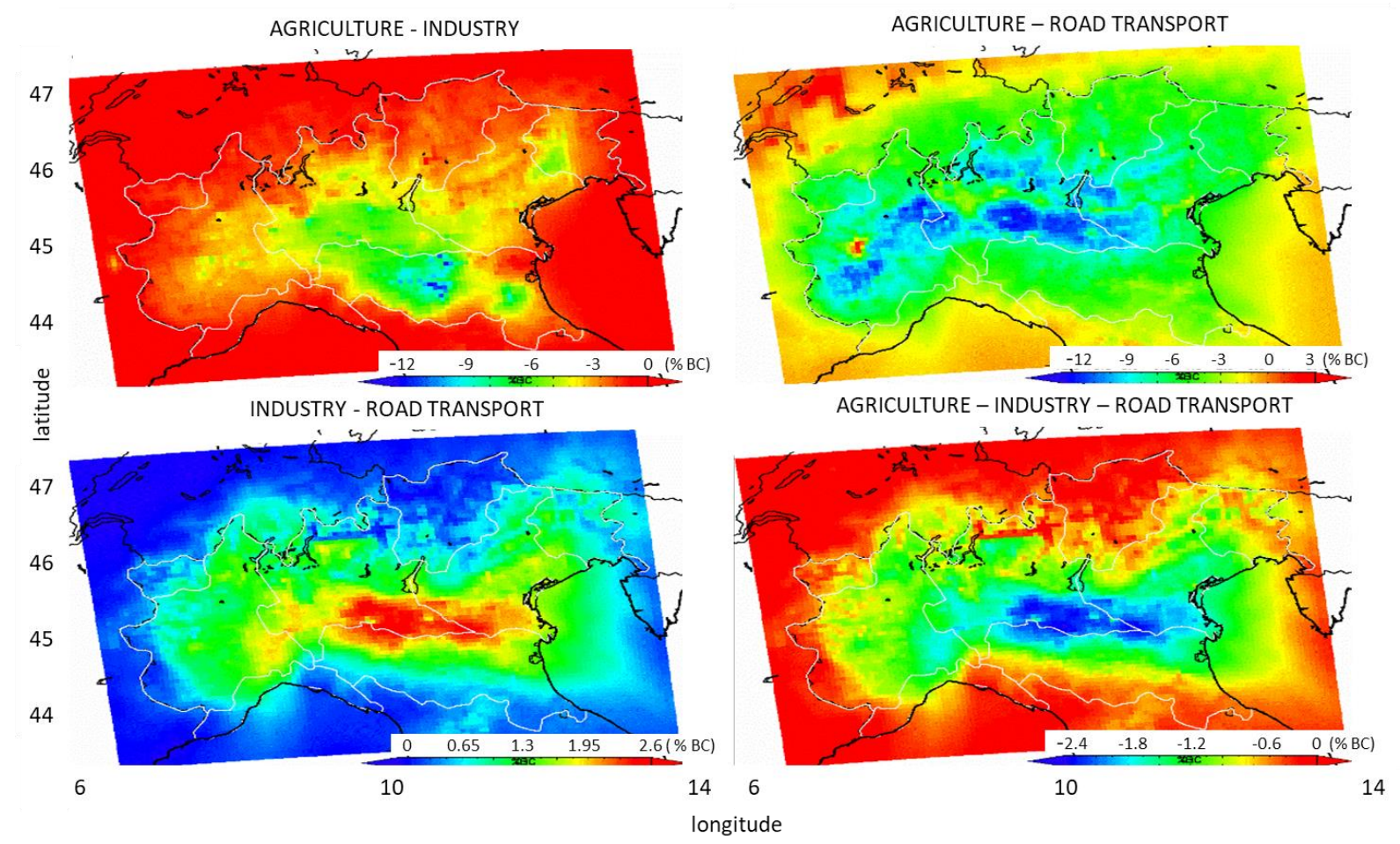

Figure S11 Map of the binary and ternary interaction terms of the PM 10 factor decomposition for AGR, IND and TRA in the CAMx $100 \%$ scenarios expressed as percentage of the base case. 


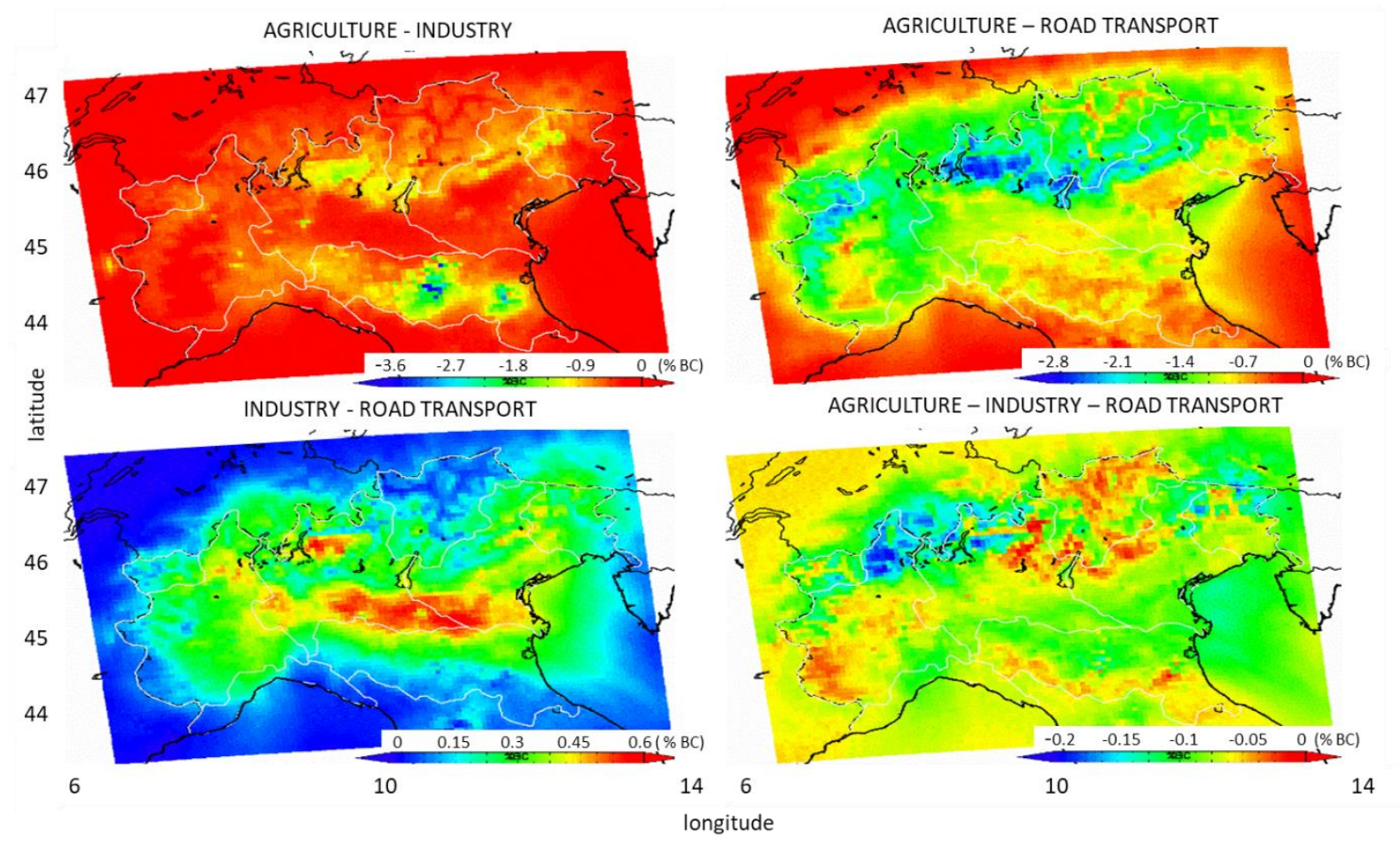

Figure S12 Map of the binary and ternary interaction terms of the PM 10 factor decomposition for AGR, IND and TRA in the CAMx $50 \%$ scenarios expressed as percentage of the base case. 